Int. J. Electrochem. Sci., 15 (2020) 1287 - 1301

\title{
Corrosion Inhibition Effect of Three Imidazolium Ionic Liquids On Carbon Steel In Chloride Contaminated Environment
}

\author{
Jingshun Cail, ${ }^{1, *}$ Jiaping $\mathrm{Liu}^{2 *}$, Song Mu ${ }^{l}$, Jianzhong Liu ${ }^{l}$, Jinxiang Hong ${ }^{l}$, Xiaochen Zhou ${ }^{l}, Q i$ Ma $^{l}$, \\ Liang $S h i^{1,3}$ \\ ${ }^{1}$ State Key Laboratory of High Performance Civil Engineering Materials, Jiangsu Sobute New \\ Materials Co., Ltd., Nanjing 211103 (P. R. China) \\ 2 Jiangsu Key Laboratory of Construction Materials, College of Materials Science and Engineering, \\ Southeast University, Nanjing 211189 (P. R. China) \\ ${ }^{3}$ Shanghai Suke Construction technology development Co. Ltd., Shanghai 201399 (P.R. China) \\ *E-mail: caijingshun@gmail.com, liujiaping@cnjsjk.cn
}

doi: $10.20964 / 2020.02 .12$

Received: 19 August 2019 / Accepted: 29 September 2019 / Published: 31 December 2019

Three imidazolium-type ionic liquids, substituted with polar groups at N1 and alkyl chains at N3 were synthesized under mild reaction conditions. The corrosion inhibition of carbon steel in $0.3 \mathrm{M} \mathrm{NaCl}$ saturated $\mathrm{Ca}(\mathrm{OH})_{2}$ solution was investigated. Influence of concentration corrosion inhibition effectiveness was obtained by potentiodynamic polarization and electrochemical impedance spectroscopy. Imidazolium ionic liquid acted as a mixed type of inhibitor by both chemical and physical adsorption on the steel surface in terms of the Langmuir adsorption isotherm. All ionic liquids showed appreciable inhibition efficiency, and the relationship between chemical structure and inhibition activity was revealed. Surface analysis suggested that imidazolium ionic liquids could effectively inhibit the formation of corrosion products.

Keywords: carbon steel; corrosion inhibitor; imidazolium ionic liquid; synthesis

\section{FULL TEXT}

(C) 2020 The Authors. Published by ESG (www.electrochemsci.org). This article is an open access article distributed under the terms and conditions of the Creative Commons Attribution license (http://creativecommons.org/licenses/by/4.0/). 